\title{
Liver Carcinosarcoma
}

National Cancer Institute

\section{Source}

National Cancer Institute. Liver Carcinosarcoma. NCI Thesaurus. Code C96848.

An aggressive carcinoma with a sarcomatous component that arises from the liver. The sarcomatous component is clonally related to the more differentiated, carcinomatous component. The prognosis is usually poor. 